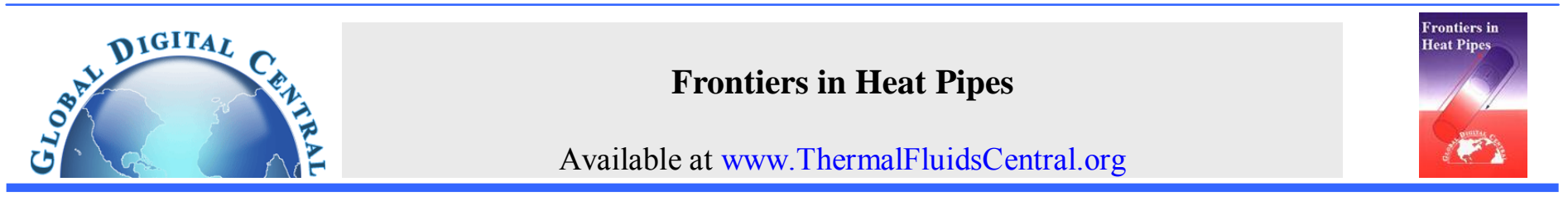

\title{
THERMAL PERFORMANCE OF TWO-PHASE CLOSED THERMOSYPHON IN APPLICATION OF CONCENTRATED THERMOELECTRIC POWER GENERATOR USING PHASE CHANGE MATERIAL THERMAL STORAGE
}

\author{
Lippong Tan", Randeep Singh, Abhijit Date, Aliakbar Akbarzadeh
}

\author{
Energy CARE Group, School of Aerospace, Mechanical, Manufacturing Engineering, RMIT University, Bundoora, Victoria, 3083, Australia
}

\begin{abstract}
A passive cooling system which uses two-phase closed thermosyphon and phase change material thermal storage for operating concentrated thermoelectric generator (CTEG) is proposed and discussed in the paper. The CTEG system can generate thermoelectricity by provide a temperature difference across thermoelectric cells which can be achieved via concentrated solar flux and the proposed passive cooling system using latent heat storage concept. To enhance the heat transfer process, thermosyphon (wickless heat pipe) is implemented as an effective heat transporting device for transferring excess heat from the cold side of the thermoelectric module to the PCM storage tank for heat storage. The aim of this investigation is to evaluate the thermal performance and electrical power output of the proposed passive cooling system. The numerical simulation shows that solar concentration of 75 suns is able to deliver maximum temperature difference of $150^{\circ} \mathrm{C}$ across thermoelectric module which does not exceed the thermoelectric cell's malfunction temperature of $250^{\circ} \mathrm{C}$ as recommended by the manufacturers.
\end{abstract}

Keywords: Two-phase closed thermosyphon, PCM, thermal storage, thermoelectric generator

\section{INTRODUCTION}

Concentrated thermoelectric generator (CTEG) system uses concentrated solar radiations as a sustainable heat source for operating the thermoelectric generator. Basically, thermoelectric generator contains one or more thermoelectric cells (TECs) which are electrically connected in series for higher voltage output or in parallel for higher current output depending on the desired application requirement. It is also a single state electrical power generator where it requires a temperature difference across the hot and cold side of the cell for thermoelectricity generation. To fulfill this pre-requisite, an effective cooling system must be installed at the cold side for heat dissipation to achieve greater temperature difference for higher power generation and also avoid cell damage. It is known that active cooling devices such as using electrical powered air and water cooling systems have gained popularity in electronic cooling as good thermal control and compact installation. However, the main drawback is power consumption which required for operating the devices significantly reduces the useful power generated by the CTEG system. Hence, passive cooling approaches would be more reliable method for CTEG system in spite of the lower cooling rate.

Main problem arises on passive cooling devices (i.e. passive heat sinks) is that cooling rate is dependent on the ambient conditions. Weather condition fluctuations such as wind speeds and ambient temperature can significantly affect the natural convection heat transfer rate and pose a limitation on the thermoelectric generation. To improve the existing passive cooling deficiencies, the authors have implemented phase change material thermal storage concept. Using enclosed heat exchanging unit embedded in an insulated storage tank filled with phase change material (PCM) will allow constant cooling performance as the external ambient condition is unable to influence the heat absorption or melting rate by PCM. The main challenge in this proposal is the heat transportation mechanism must be capable for transporting large amount from the heated TECs to the PCM thermal storage tank for heat storage.

In this paper, two-phase closed thermosyphons are implemented as the passive heat transporting device in the CTEG system incorporating PCM thermal storage. The objective of using these thermosyphons is to provide greater temperature difference across TECs for greater thermoelectricity. The aim of this study is to assess the thermal performance and thermo-electrical generation of the CTEG system under different solar concentrating ratios. The optimum thermoelectric power output is only achieved when the TECs achieve the greatest temperature difference without exceeding the maximum operating cell temperature of $250^{\circ} \mathrm{C}$ recommended by TEG manufacturer.

\section{CONCEPT DESIGN}

In this present design shows in Fig. 1, two thermosyphons or gravity-assisted heat pipes are utilized in the CTEG system. The advantages of using these devices are simple structural construction and the ability to transfer large quantity of heat with a small temperature drop (Hagens and Ganzevles, 2007) that made it favorable as a heat transporting device in this proposed passive cooling concept.

The incoming heat source is delivered by the concentrated solar flux via Fresnel lens concentrator. The top panel (hot side) of the thermoelectric module rapidly heat up and the bottom panel (cold side) requires effective cooling to achieve temperature difference across the TECs for thermoelectricity generation. Copper material is used as heat

* Corresponding author. Email: lippong.tan@rmit.edu.au 
collector and heat sink due to the high thermal conductivity $(380 \mathrm{~W} / \mathrm{m}$ $\mathrm{K})$ and high corrosive resistance. The TECs in the thermoelectric module are sandwiched by the copper blocks to provide a temperature gradient between the top panel (hot side) and bottom panel (cold side).

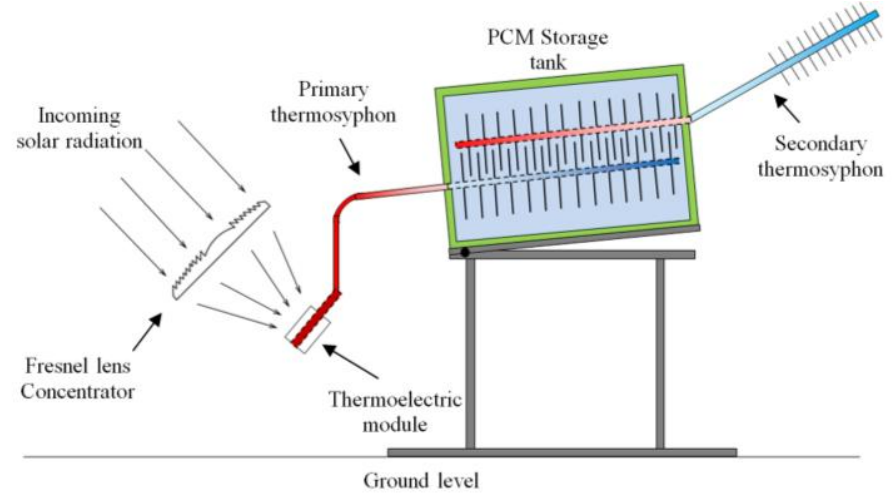

Fig. 1 Schematic diagram of proposed CTEG-PCM cooling system.

Two thermosyphons are utilized in the system for dissipating the heat from one point to the other during day and night operation. The primary thermosyphon is used for transferring heat from the thermoelectric module to the PCM storage tank for heat absorption (melting process) during the day. There is a secondary thermosyphon which embedded in the PCM storage tank is designed for transporting heat from the melted PCM (freezing process) to the cooler surrounding during the night in preparation for the next day cycle. Passive cooling cycle in this concept design is formulated through repetitive melting and freezing of the PCM thermal storage where thermosyphons play important roles in excess heat transportation and dissipation.

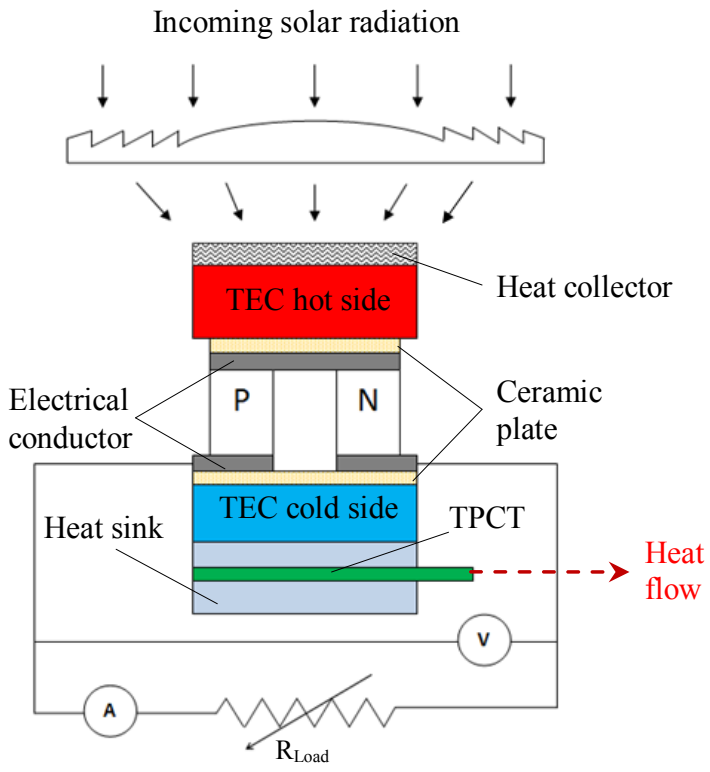

Fig. 2 Schematic thermoelectric module and heat flow.

Fig. 2 shows the schematic diagram of thermoelectric module with the incoming concentrated solar flux as heat source via Fresnel lens concentrator. The top panel (hot side) of the TEC rapidly heat up and the bottom panel (cold side) will be cooled by the copper heat sink which coupled by thermosyphon to achieve temperature difference. The outer pipe diameter of the primary thermosyphon on the experimental prototype shows in Fig. 3 is $15.9 \mathrm{~mm}$ and the evaporator section is thermally inserted into copper heat sink.

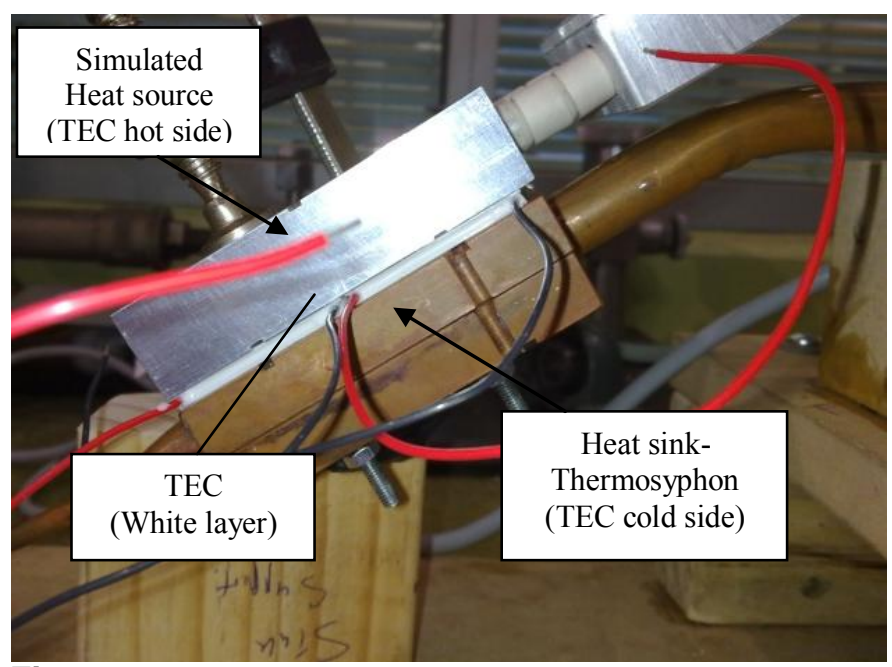

Fig. 3 Thermoelectric module in the experimental rig using heater as simulated heat source for indoor experiment.

In the PCM storage tank, the secondary thermosyphon which embedded in the PCM is designed to remove the stored heat in the melted PCM to the cooler surrounding night temperature upon reaching it saturation temperature of $20^{\circ} \mathrm{C}$. It also acts as a thermal diode where it prevents heat from the external ambient to infiltrate into the PCM storage tank, reducing the heat storage capacity.

\section{Insulated tank wall}

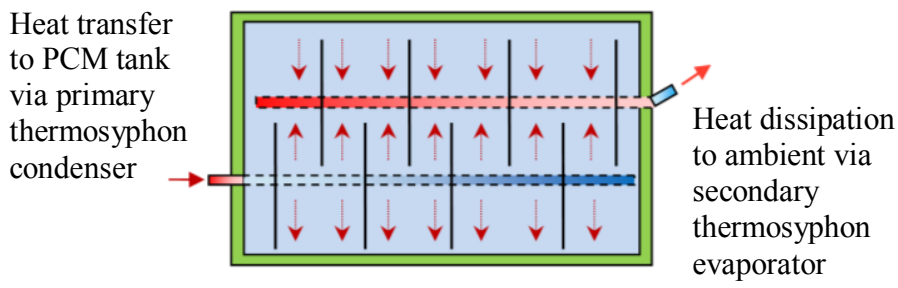

Fig. 4 Thermosyphons embedded in PCM storage tank.

The PCM used in the thermal storage tank is commercial paraffin wax. It is non-corrosive, readily off-the-shelves and has high latent heat storage capacity which make it attractive to be used in the thermal storage system. It is noted that paraffin wax has low thermal conductivity $(0.2 \mathrm{~W} / \mathrm{m} \mathrm{K})$ which may affect the heat exchanging performance by the thermosyphons during melting and freezing. Approach taken for improving the PCM melting is by using longer thermosyphon condenser section (1 evaporator length : 3 condenser length) and incorporate aluminum fin attachments for providing a larger heat transfer surface area to improve the effective thermal conductivity within the PCM storage. To avoid dry-out occurrence, both thermosyphons are tiled at $5^{\circ}$ angles for facilitating the return of condensate to the evaporator sections. In addition, PCM storage tank is required to be elevated above the thermoelectric module to ensure the thermosyphon condenser section is above the evaporator section.

In this numerical investigation, it is essential to understand the specific heat capacity variations over temperature of the PCM during melting and freezing process. Samples of paraffin wax $(\sim 10 \mathrm{mg})$ were sent to RMIT chemical department for scanning using the differential scanning calorimetry (DSC) method. The DSC results in Fig. 5 shows that the peak melting temperature is $47^{\circ} \mathrm{C}$ with latent heat of $\sim 140 \mathrm{~kJ} / \mathrm{kg}$. Further information on the thermo-physical properties of the proposed paraffin wax are summarized in table 1 . 


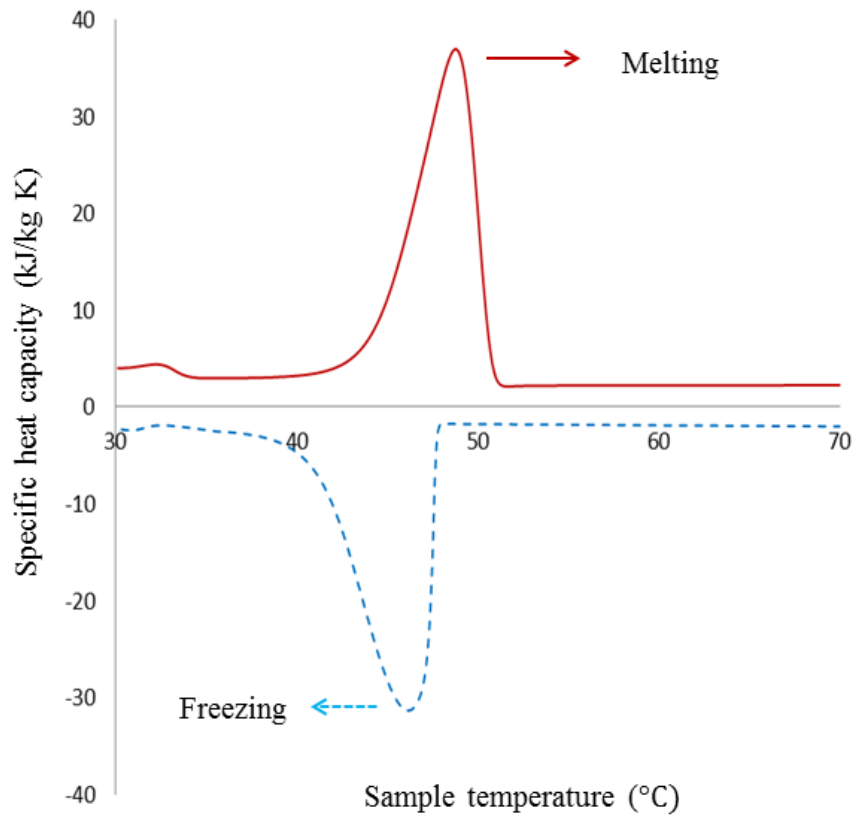

Fig. 5 DSC results for proposed commercial paraffin wax

Table 1 Thermo-physical properties of proposed paraffin wax.

\begin{tabular}{|l|c|}
\hline Description & Value \\
\hline Melting temperature $\left[{ }^{\circ} \mathrm{C}\right]$ & 47 \\
\hline Solid density $\left[\mathrm{kg} / \mathrm{m}^{3}\right]$ & 880 \\
\hline Liquid density $\left[\mathrm{kg} / \mathrm{m}^{3}\right]$ & 760 \\
\hline Latent heat capacity $[\mathrm{kJ} / \mathrm{kg}]$ & 140 \\
\hline $\begin{array}{l}\text { Specific heat capacity }[\mathrm{kJ} / \mathrm{kg} \mathrm{K}] \\
\text { (Solid/liquid) }\end{array}$ & $2.9 / 2.2$ \\
\hline Thermal conductivity $[\mathrm{W} / \mathrm{m} \mathrm{K}]$ & 0.2 \\
\hline
\end{tabular}

\section{SYSTEM MODELLING}

The energy balance equation for the CTEG-PCM system is given by:

$\dot{Q}_{\text {input }}=\dot{Q}_{\text {conv }}+\dot{Q}_{\text {rad }}+P_{\text {tec }}+\dot{Q}_{s y s}$

The incoming solar radiation $q_{\text {rad }}^{\prime \prime}$ is the solar radiant energy input on the collector area $A_{c o}$ of $80 \mathrm{~mm}$ (length) and $40 \mathrm{~mm}$ (width). The optical efficiency $n_{\text {len }}$ of Fresnel lens concentrator and the absorptive of the copper heat collector $n_{a b s}$ are assumed as $80 \%$ in this modeling. The concentrated heating power governed by solar concentration ratio $C R$ on heat collector is written as:

$$
\dot{Q}_{\text {input }}=n_{\text {len }} \times n_{\text {abs }} \times q_{\text {rad }}^{\prime \prime} \times A_{c o} \times C R
$$

Ambient energy losses by convection $\dot{Q}_{\text {conv }}$ and radiation $\dot{Q}_{\text {rad }}$ heat transfer will be accounted in the net energy absorbed into the system.

$\dot{Q}_{\text {conv }}=h_{\text {air }} A_{c o}\left(T_{c o}-T_{\text {amb }}\right)$

$\dot{Q}_{\text {rad }}=\varepsilon \sigma A_{c o}\left(T_{c o}^{4}-T_{a m b}^{4}\right)$
The assumption made for heat losses to the surrounding by the copper absorber plate is through convention and radiation heat transfer under the ambient conditions of wind speed $V_{\text {air }}$ of $2 \mathrm{~m} / \mathrm{s}$ and ambient temperature $T_{a m b}$ at $20^{\circ} \mathrm{C}$. The Stefan-Boltzmann's constant $(\sigma=5.67 \mathrm{x}$ $10^{-8} \mathrm{Wm}^{-2} \mathrm{~K}^{-4}$ ) is applied to radiation heat transfer and convective heat transfer coefficient for top surface of the solar collector plate which is estimated by $h_{\text {air }}=5.7+3.8 V_{\text {air }}$ (McAdam, 1954).

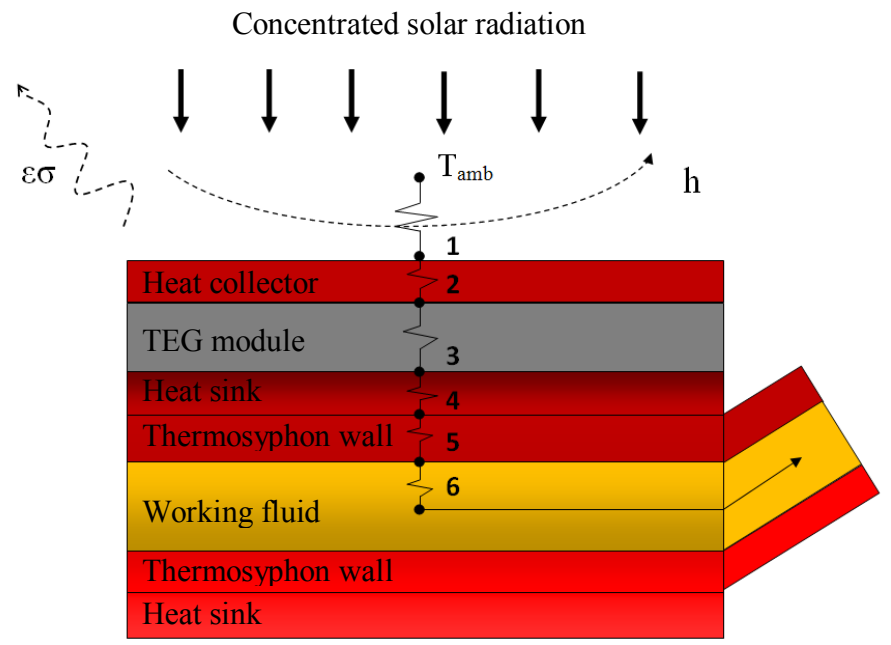

Fig. 6 Thermal resistance networks diagram for thermoelectric module to primary thermosyphon.

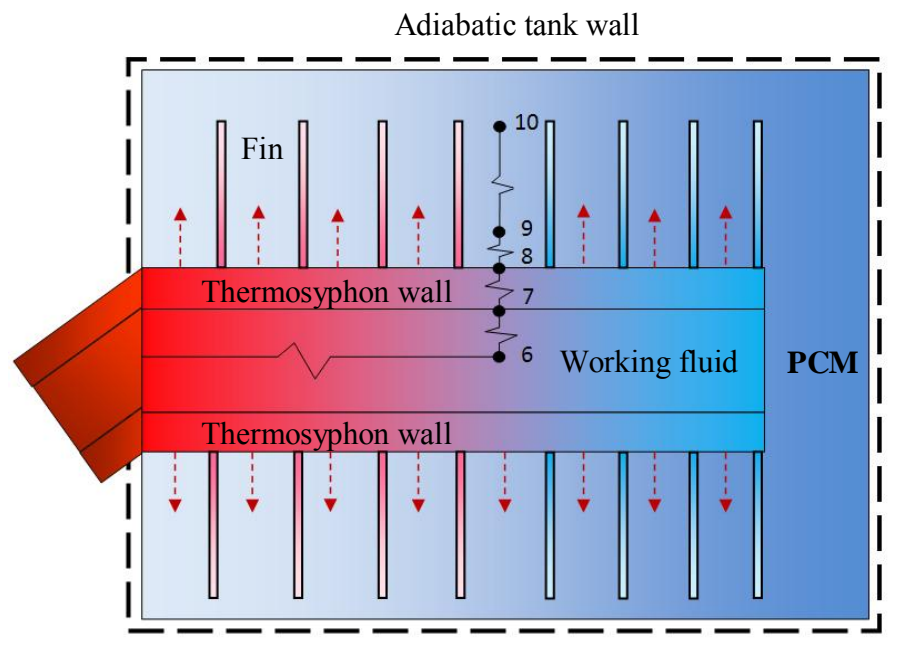

Fig. 7 Thermal resistance networks diagram for primary thermosyphon to PCM thermal storage tank.

Fig. 6 and 7 present the lumped thermal resistance networks diagrams for the overall CTEG-PCM system. As PCM undergoes phase change upon reaching its melting point, the heat capacity will vary with the temperature increment. Hence, finite difference method (Holman J.P., 2002) will be utilized for solving the one-dimensional temperature-dependent equations.

$q_{i}+\sum_{j} \frac{T_{j}^{p}-T_{i}^{p}}{R_{i j}}=C_{i} \frac{T_{i}^{p+1}-T_{i}^{p}}{\Delta t}$

where $q_{i}$ and $\Delta t$ is the input concentrated solar power and time step respectively. 
The system heat transfer equation is given by:

$$
R_{1-2}=R_{3-4}=\frac{t_{c o}}{K_{c o} A_{c o}}=\frac{t_{s p}}{K_{s p} A_{s p}}
$$

where

$$
R_{2-3}=\frac{t_{t e c}}{K_{t e c} A_{t e c}}
$$

Fig. 8 shows the experimental prototype fabricated in RMIT University. To examine on the passive concept using thermosyphons and PCM thermal storage, the framework of this numerical modeling will solely base on PCM cooling process (melting) where only primary thermosyphon is considered in the system modeling. Hence, freezing process via secondary thermosyphon will not be included.

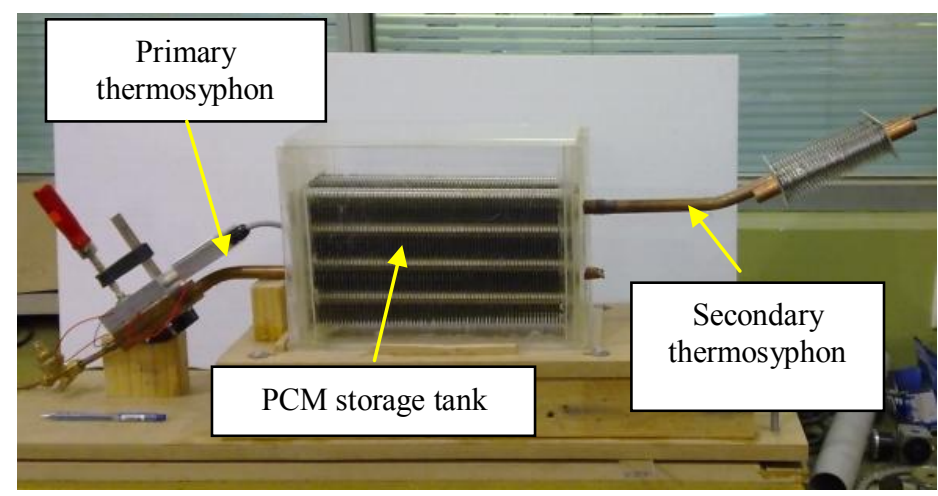

Fig. 8 Overview of TEC-PCM system: Side view.

\subsection{Thermal resistance for the wall of thermosyphon}

The thermal resistance of thermosyphon wall is a function of its sectional length and pipe thickness.

Evaporator section:

$R_{4-5}=\frac{\ln \left(\frac{r_{o}}{r_{i n}}\right)}{2 \pi L_{e} K_{c u}}$

\section{Condenser section:}

$R_{7-8}=\frac{\ln \left(\frac{r_{o}}{r_{i n}}\right)}{2 \pi L_{c} K_{c u}}$

\subsection{Heat transfer within thermosyphon:}

The selected working fluid is Acetone. It has lower boiling point $\left(55^{\circ} \mathrm{C}\right)$ at atmospheric pressure and latent heat of vapourization of $527 \mathrm{~kJ} / \mathrm{kg}$. The designated saturated temperature for the cooling system is $50^{\circ} \mathrm{C}$. The thermal resistances for convective heat transfer by vapourization and condensation of working fluid are shown below.

Evaporator section :

$R_{5-6}=\frac{1}{h_{e} A_{e}}$
Condenser section:

$$
R_{2-3}=\frac{1}{h_{c} A_{c}}
$$

The heat transfer coefficients within the thermosyphon are assumed under the working condition where only minimum fill volume of the working fluid is required for maintaining liquid flim on the wall of the thermosyphon. The simplified average heat transfer coefficients for both evaporator and condenser sections are given by the classical Nusselt analysis (Faghri, 1995)

Evaporator section:

$h_{e}=\left[\frac{\rho_{l}^{2} k^{3} g h_{f g}}{4 \mu_{l}\left(T_{5}-T_{s a t}\right) L_{e}}\right]^{1 / 4}$

Condenser section:

$h_{c}=\left[\frac{\rho_{l}^{2} k^{3} g h_{f g}}{4 \mu_{l}\left(T_{s a t}-T_{7}\right) L_{c}}\right]^{1 / 4}$

\subsection{Thermal resistance between the condenser fin attachment and PCM}

Paraffin wax will undergo phase change (solid-liquid) upon reaching its melting point under constant heat dissipation by the thermosyphon condenser. It is noted that conduction heat transfer will gradually diminish as natural convection heat transfer grow rapidly during solid-liquid state transition. However, the close fin gaps $(4 \mathrm{~mm})$ of the aluminum heat exchange unit will significantly hamper the natural convection effect and become heat conduction dominant. Hence, only pure conduction is assumed throughout the phase changing process. The thermal resistance for solid PCM within the aluminum fin gap is given by:

$R_{8-9}=\frac{L_{f i n}}{2 K_{f i n} A_{f i n}}+\frac{L_{p c m}}{K_{p c m} A_{p c m}}$

As stated previously, paraffin wax as PCM has high latent heat of $140 \mathrm{~kJ} / \mathrm{kg}$ and melting temperature of $47^{\circ} \mathrm{C}$. The conditional governing equations for heat storage in the PCM thermal storage are given as:

Solid phase: $T_{a m b}<T_{p c m}<T_{m e l t}$

$Q_{p c m}=m_{p c m} C_{s}\left(T_{p c m}-T_{a m b}\right)$

Solid-liquid Phase: $T_{\text {amb }}=T_{\text {melt }}$

$Q_{p c m}=m_{p c m}\left\lfloor C_{s}\left(T_{m e l t}-T_{a m b}\right)+H\right\rfloor$

Liquid Phase: $T_{a m b}>T_{\text {melt }}$

$Q_{p c m}=m_{p c m}\left[C_{s}\left(T_{m e l t}-T_{a m b}\right)+H\right]+m_{p c m} C_{l}\left(T_{p c m}-T_{a m b}\right)$

\section{RESULTS AND DISCUSSIONS}

The numerical model for the CTEG-PCM system has been completely developed in MATLAB programming software. The 
numerical results predict the thermal and electrical performance of the CTEG-PCM system based on the intended experiment conditions. Different solar concentrations will be simulated to determine the maximum solar concentration for achieving the optimum thermoelectricity production by the thermoelectric module.

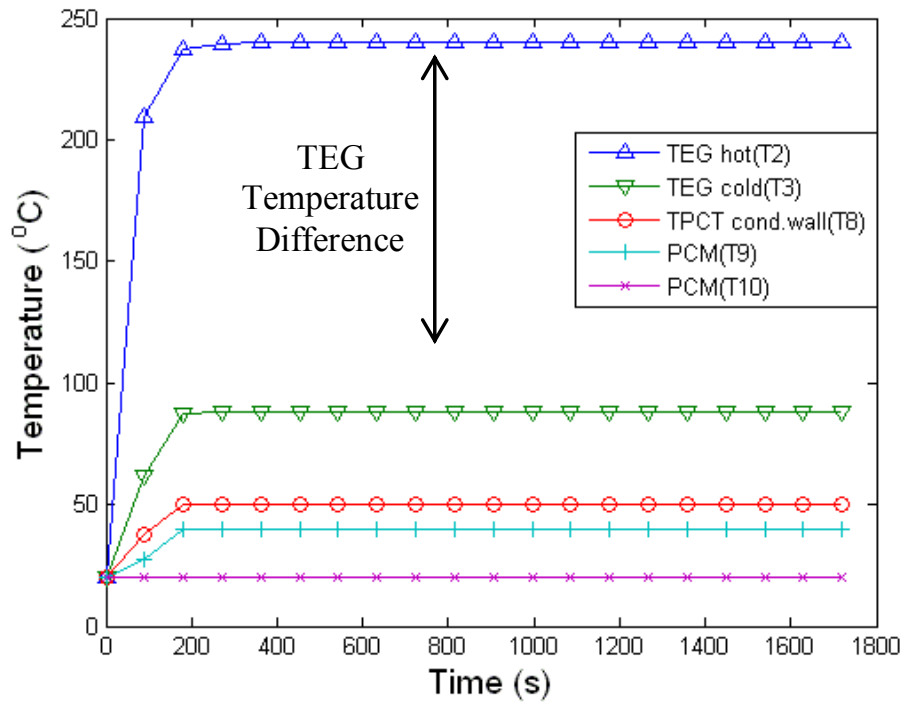

Fig. 9 Thermal performance of CTEG-PCM system $(\mathrm{CR}=75)$.

Fig. 9 shows the overall thermal performance of TEG-PCM system under 75 suns over 1700s (30mins) duration. The simulation assumes that all dissipated heat energy via the primary thermosyphon is fully absorbed by the PCM thermal storage. Based on this assumption, the maximum TEC hot side temperature at the thermoelectric module has reached $240^{\circ} \mathrm{C}$ where the maximum temperature limit recommended by TEC manufacturer is $250^{\circ} \mathrm{C}$. Hence, the maximum solar concentration (CR) for this configuration is 75 suns. The aperture diameter of the Fresnel lens should be sized at $560 \mathrm{~mm}$. The TEC cold side temperature has also maintained at $88^{\circ} \mathrm{C}$ and attained a constant TEC temperature difference of $152^{\circ} \mathrm{C}$ over this period. Both temperature on the TEC hot and cold side decrease rapidly when the evaporator temperature reaches the saturation temperature $\left(60^{\circ} \mathrm{C}\right)$ of the working fluid in the primary thermosyphon. The significant drop at the TEC cold side shows that waste heat has effectively transferred from the evaporator section to the condensation section embedded in the PCM thermal storage for heat dissipation.

The dissipated heat is absorbed by the PCM as sensible heat before 200 seconds and thereafter latent heat absorption upon reaching the melting point $\left(47^{\circ} \mathrm{C}\right)$. The PCM temperatures (T9 and $\left.\mathrm{T} 10\right)$ located at $10 \mathrm{~mm}$ and $50 \mathrm{~mm}$ above the primary thermosyphon condenser are designated to capture melting performance during heat absorption. T9 has rose gradually and later become plateau due to the latent heat of fusion (PCM melting) of the paraffin wax. At this plateau region, PCM continued to absorb dissipated heat despite there was no rise in temperature.

The thermoelectric cells in the TEG module are made of Bismuth Telluride $\left(\mathrm{Bi}_{2} \mathrm{Te}_{3}\right)$ which has high Seebeck coefficient $(\sim 190 \mu \mathrm{V} / \mathrm{K})$ and high figure of merit $\left(\sim 2 \times 10^{-3} \mathrm{~K}^{-1}\right)$ (Slack G.A, 1994). Fig. 11 shows the thermoelectric power outputs over different solar concentration ratios. The maximum theoretical power output was $9.5 \mathrm{~W}$ under maximum temperature difference of $152^{\circ} \mathrm{C}$. Further temperature difference cannot be achieved on the existing configuration as the TEC hot side panel temperature will exceed the maximum operating temperature $\left(250^{\circ} \mathrm{C}\right)$. Using working fluid with lower saturation temperature and higher latent heat of vaporization in thermosyphon can further attain greater temperature difference for higher thermoelectric power output.

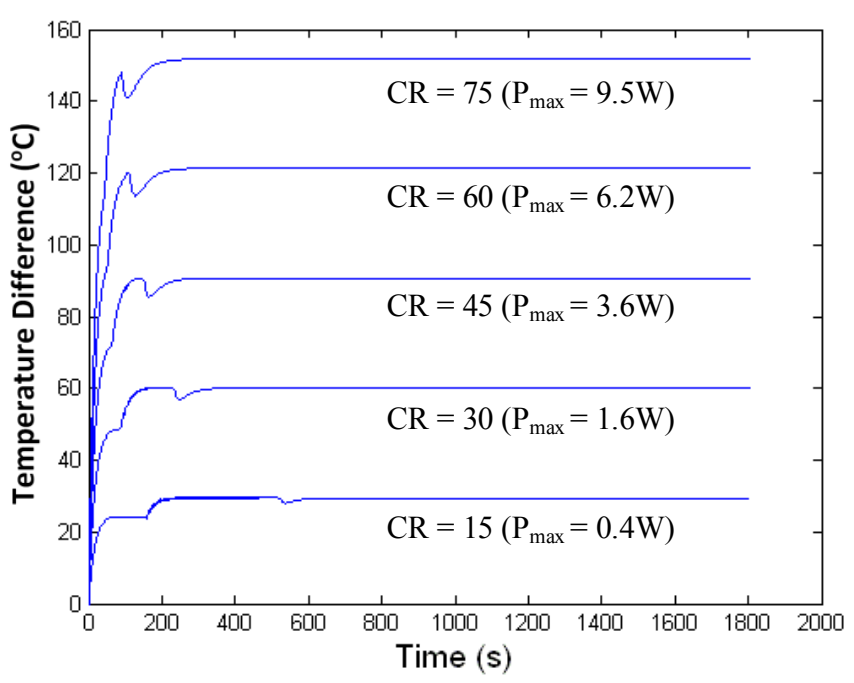

Fig. 10 Temperature difference and power output for 2 TECs under different solar concentrations.

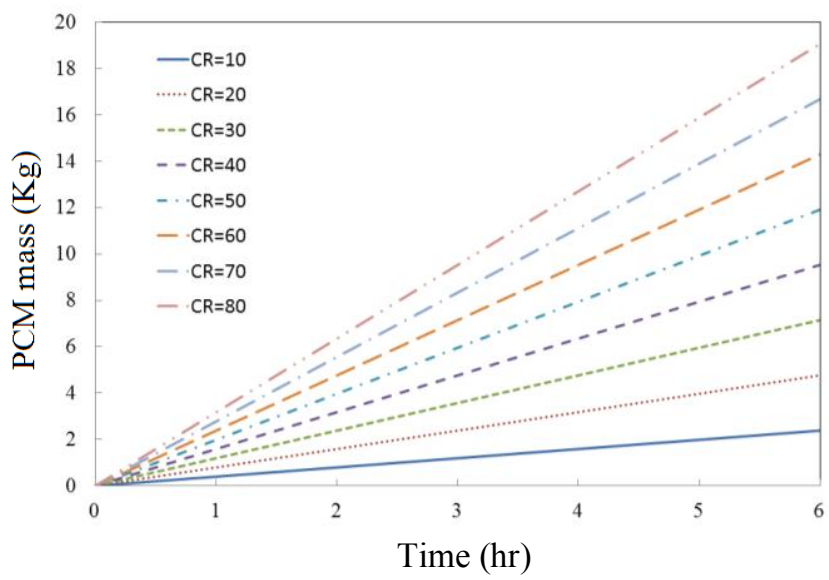

Fig. 11 PCM requirement over solar concentration ratios

The CTEG-PCM system is designed operate six hours a day for thermoelectricity generation. Hence, the amount of PCM must be sufficient in the storage tank for heat absorption and cool the thermoelectric module under concentrated solar radiation. Fig. 11 shows the estimated amount of PCM masses which requires for operation under solar concentrations over experimental time.

\section{CONCLUSION}

In this present study, the thermal performance of the concentrated thermoelectric generator utilizing two phase closed thermosyphon as heat transfer device has been investigated numerically. Some conclusions are drawn as follows:

- Thermosyphon has shown to be an effective heat transporting device due to simple structural construction and it can be easily bent to fit and connect between the CTEG system and PCM thermal storage.

- The simulation had shown that using passive devices; thermosyphon and PCM thermal storage are able to maintain a temperature difference of $152^{\circ} \mathrm{C}$ and produce $9.5 \mathrm{~W}$ of thermoelectric power.

- $\quad$ Although PCM provides large amount of heat storing capacity and enable constant cooling on TEG cold side panel, more researches need to be done on improving the PCM thermal conductivity to maximize the heat absorption rate.

- More researches need to be done on working fluid selection for lowering the cold side temperature of the TEC to achieve greater temperature difference. 


\section{ACKNOWLEDGEMENTS}

The authors wish to thank Dr. Panniselvam from Department of Chemical Engineering RMIT University for his kind support in providing thermo-physical properties of the paraffin wax.

\section{NOMENCLATURE}

$\begin{array}{cl}\dot{Q} & \text { energy per unit time } \\ P_{t e c} & \text { thermoelectric power } \\ n & \text { efficiency } \\ A & \text { area }\left(\mathrm{m}^{2}\right) \\ \mathrm{CR} & \text { concentration ratio } \\ h & \text { convection } \\ T & \text { temperature } \\ q & \text { heat flux } \\ \mathrm{R} & \text { resistance } \\ \Delta t & \text { time step } \\ \mathrm{K} & \text { thermal conductivity } \\ \mathrm{r} & \text { radius } \\ \mathrm{L} & \text { length } \\ \mathrm{m} & \text { mass } \\ \mathrm{H} & \text { latent heat of fusion } \\ \mathrm{C} & \text { Specific heat }\end{array}$

\section{Greek Symbols}

$\begin{array}{ll}\varepsilon & \text { total emissivity } \\ \rho & \text { density }\left(\mathrm{kg} / \mathrm{m}^{3}\right) \\ \sigma & \text { Stefan-Boltzmann constant }\left(\mathrm{W} / \mathrm{m}^{2} \cdot \mathrm{K}^{4}\right)\end{array}$

\section{Superscripts \\ $P \quad$ initial time step \\ $P+1 \quad$ future time step}

$\begin{array}{ll}\text { Subscripts } & \\ i & \text { initial spatial } \\ j & \text { future spatial } \\ \text { input } & \text { input } \\ \text { conv } & \text { convection }\end{array}$

$\begin{array}{ll}\text { rad } & \text { radiation } \\ \text { tec } & \text { thermoelectric cells } \\ \text { sys } & \text { system } \\ \text { len } & \text { len } \\ \text { co } & \text { collector } \\ \text { sp } & \text { spreader } \\ \text { air } & \text { air } \\ \text { amb } & \text { ambient } \\ e & \text { evaporator } \\ c & \text { condenser } \\ \text { cu } & \text { copper } \\ l & \text { liquid } \\ \text { fg } & \text { fusion } \\ \text { sat } & \text { saturation } \\ \text { pcm } & \text { phase change material } \\ \text { amb } & \text { ambient } \\ \text { fin } & \text { aluminum fin } \\ s & \text { solid } \\ \text { melt } & \text { melting point } \\ o & \text { outer } \\ \text { in } & \text { inner } \\ \text { abs } & \text { absorption }\end{array}$

\section{REFERENCES}

Faghri A., 1995, Heat pipe science and technology, USA, BraunBrumfield Inc., 1995, USA.

Holman J.P., 2002, Heat Transfer, $9^{\text {th }}$ edition, Von Hoffman Press Inc., New York.

Incropera, F.P., DeWitt, D.P., Bergman, T.L., and Lavine, A.S., 2007, Fundamentals of Heat and Mass Transfer, $6^{\text {th }}$ ed., John Wiley \& Sons, Hoboken, NJ.

McAdam, W.H., 195, Heat Transmission, $3^{\text {rd }}$ editions, McGraw-Hill Book Company. USA.

Slack G.A., 1994, New materials and performance limits for thermoelectric cooling, In: Rowe D.M., editor. CRC Handbook on Thermoelectrics. CRC Press, UK.

H.F. Hagens, L. A. Ganzevles, 2007, Air heat exchangers with long heat pipes: Experiments and predictions, Applied Thermal Engineering 27(14-15): 2426-2434.

http://dx.doi.org/10.1016/j.applthermaleng.2007.03.004 